\title{
Perceived racism and incident diabetes in the Black Women's Health Study
}

\author{
Kathryn L. Bacon ${ }^{1}$ - Sherri O. Stuver ${ }^{1}$ - Yvette C. Cozier ${ }^{1,2}$ • Julie R. Palmer ${ }^{1,2}$ • \\ Lynn Rosenberg ${ }^{1,2} \cdot$ Edward A. Ruiz-Narváez $^{1,2}$
}

Received: 3 February 2017 / Accepted: 6 July 2017 /Published online: 15 August 2017

(C) Springer-Verlag GmbH Germany 2017

\begin{abstract}
Aims/hypothesis Our aim was to assess the association of perceived racism with type 2 diabetes, and the possible mediating influence of diet and BMI.

Methods The Black Women's Health Study, a follow-up of 59,000 African-American women, began in 1995. Over 16 years 5344 incident cases of diabetes occurred during 576,577 person-years. Cox proportional hazards models were used to estimated HRs and 95\% CIs for categories of 'everyday racism' (interpersonal racism in daily life) and 'lifetime racism' (reporting ever treated unfairly due to race with respect to police, housing or work) and incident type 2 diabetes. Models were adjusted for age, questionnaire cycle, marital status, socioeconomic status, education, family history of diabetes, physical activity, alcohol use and smoking status, with and without inclusion of terms for dietary patterns and adult BMI.

Results Compared with women in the lowest quartile of exposure, women in the highest quartile of exposure to everyday racism had a $31 \%$ increased risk of diabetes (HR $1.31 ; 95 \%$ CI $1.20,1.42$ ) and women with the highest exposure to lifetime racism had a $16 \%$ increased risk (HR $1.16 ; 95 \%$ CI $1.05,1.27)$. Mediation analysis estimated that BMI accounted for half of the association between either the everyday or lifetime racism measure and incident diabetes.
\end{abstract}

Edward A. Ruiz-Narváez

eruiznar@bu.edu

1 Department of Epidemiology, Boston University School of Public Health, Boston, MA, USA

2 Slone Epidemiology Center at Boston University, Boston University Medical Campus, 72 East Concord Street, L-7, Boston, MA 02118, USA
Conclusions/interpretation Perceived everyday and lifetime racism were associated with increased risk of type 2 diabetes in this cohort of African-American women and appear to be at least partly mediated by BMI.

Keywords Black women $\cdot$ Diabetes $\cdot$ Obesity $\cdot$ Racial discrimination $\cdot$ Racism $\cdot$ Stress

\author{
Abbreviations \\ BWHS Black Women's Health Study \\ SES Socioeconomic status
}

\section{Introduction}

The prevalence of type 2 diabetes among African-American women is double that in non-Hispanic white women [1]. Differences in traditional risk factors, including BMI and socioeconomic status (SES), do not fully explain this racial disparity [2].

Racial discrimination is a critical psychosocial stressor for African-American people, who experience racism more frequently than other ethnic groups [3], and may contribute to observed differences in health between African-Americans and white Americans.

To our knowledge, no prospective studies have been conducted regarding perceived racism and type 2 diabetes incidence, although we have evaluated racism in relation to weight gain and incident obesity $[4,5]$. Cross-sectional studies have found associations between perceived racism and diabetes-related outcomes [6-8].

In the current study, we evaluated the association of perceived racism with incident type 2 diabetes using data from the Black Women's Health Study (BWHS). We hypothesised 
that women with high levels of perceived racism would have higher risk of type 2 diabetes. We assessed whether BMI and diet are mediators of the relationship.

\section{Methods}

Study population The BWHS is a prospective follow-up study that enrolled approximately 59,000 African-American women aged 21-69 years at baseline in 1995 [9]. The cohort is followed every 2 years using postal questionnaires to update information including diagnosis of diabetes. The study protocol is approved by the institutional review board of Boston University. Follow-up has been successful for $87 \%$ of potential person-years of follow-up up to 2013.

Diabetes assessment Follow-up questionnaires up to 2013 asked about new diagnoses of diabetes during the previous 2 year period. Incident cases were defined as self-reported physician-diagnosed type 2 diabetes that occurred at age 30 years or older, excluding type 1 diabetes and gestational diabetes, with no report of a previous diagnosis.

In a validation study among BWHS participants, the diagnosis of diabetes was confirmed in 220 (96\%) of the 229 self-reports [10]. We estimated the prevalence of undiagnosed diabetes to be $6.4 \%$ using tests for $\mathrm{HbA}_{1 \mathrm{c}}$ in blood samples from 1873 participants who had never reported diabetes [11].

Ascertainment of perceived racism The 1997 questionnaire contained questions on perceived racism adapted from Williams et al [3]. In a validation study, we confirmed the predetermined two major domains of the racism questions [4]. We created two summary racism variables based on results from principal component analysis. An 'everyday racism' summary score averaged responses from five questions regarding the frequency of racism in daily life. Response options were 'never', 'a few times a year', 'once a month', 'once a week' and 'almost every day' and were scored 1 (never) to 5 (almost every day). Total scores were categorised into quartiles (quartile 1 lowest; quartile 4 highest). A 'lifetime racism' summary score summed the number of positive responses to three yes/no questions about experiences of 'being treated unfairly due to your race' at work, in housing or by the police. The summary score was 0 (none), 1, 2 or 3 (all) questions answered 'yes'.

Covariates Current weight, marital status, medical care use, reproductive and medical history, smoking, alcohol use, medications and physical activity were assessed in 1995 and on each subsequent follow-up questionnaire. Dietary patterns of vegetables/fruit and meat/fried food consumption were calculated from the 1995 and 2001 food frequency questionnaires. Self-reported adult height was recorded in
1995. First-degree family history of diabetes was ascertained in 1995 and 1999. Data on years of education were collected in 1995 and 2003. Marital status was recorded in 1995, 1997, 1999 and 2005. BMI was updated with each questionnaire, based on self-reported height and current weight. In a validation study of anthropometric measures conducted in 115 BWHS participants, Spearman correlations for self-reported vs technician-measured weight and height were 0.97 and 0.93 , respectively [12].

Neighbourhood SES was measured by linking participants' current address to 2000 US Census block groups using geocoding (Mapping Analytics, Rochester, NY, USA) [13]. We used factor analysis to calculate a score for neighbourhood SES, with further division into quintiles (quintile 1 lowest; quintile 5 highest).

Statistical analyses Baseline for the present analyses was 1997. There were 51,090 women who answered the perceived racism questions. We excluded women with a history of diabetes, cancer, myocardial infarction, stroke and/or coronary artery bypass graft surgery. The final sample analysed included 45,781 women.

We used Cox proportional hazards models to estimate HRs and 95\% CIs for incident type 2 diabetes. Person-years were calculated from 1997 until diagnosis of type 2 diabetes, loss to follow-up, death, occurrence of any of the exclusion criteria or end of follow-up in 2013, whichever came first. We modelled time-varying variables using the Andersen-Gill approach. We used SAS statistical software version 9.4 (SAS Institute, Cary, NC, USA).

The initial model included age and questionnaire cycle. The primary multivariate model included age, questionnaire cycle, marital status (married/living as married, separated/ divorced/widowed, single/never married), quintiles of neighbourhood SES, number of years of education $(\leq 12$, $13-15, \geq 16$ ), family history of diabetes (yes/no), vigorous physical activity ( $\mathrm{h} /$ week) $(<1,1-4, \geq 5)$, walking for exercise (h/week) ( $<1,2-3,3-4, \geq 5$ ), alcohol use (never, past, current no. of drinks/week $1-3,4-6$, or $\geq 7$ ) and smoking status (never, past, current).

We evaluated BMI and diet as potential mediators of the relationship between perceived racism and diabetes. We included time-varying categorical BMI (in $\mathrm{kg} / \mathrm{m}^{2}:<25$, 25-29, 30-34, 35-39, $\geq 40$ ) and vegetable/fruit and meat/fried food dietary pattern scores (continuous) to our multivariate model. We estimated mediation proportion and $95 \% \mathrm{CI}$ using the partial likelihood of the Cox models.

\section{Results}

Table 1 shows participant characteristics by everyday racism quartiles and by lifetime racism categories. 
Table 1 Baseline (1997) characteristics of participants in the analysis sample from the BWHS, by perceived everyday and lifetime racism

\begin{tabular}{|c|c|c|c|c|c|}
\hline \multirow[t]{2}{*}{ Characteristic } & \multirow[t]{2}{*}{ Total } & \multicolumn{2}{|c|}{ Everyday racism quartiles } & \multicolumn{2}{|c|}{ Summary lifetime racism } \\
\hline & & Q1 & Q4 & No to all & Yes to 3 \\
\hline No. of women & 45,781 & 8389 & 11,375 & 13,209 & 4911 \\
\hline Age, years (mean $\pm \mathrm{SD})$ & $40.1 \pm 10.3$ & $43.2 \pm 11.4$ & $37.8 \pm 9.2$ & $39.4 \pm 10.7$ & $41.1 \pm 9.4$ \\
\hline $\mathrm{BMI} \geq 30 \mathrm{~kg} / \mathrm{m}^{2}, \%$ & 39.2 & 35.3 & 43.0 & 37.9 & 40.2 \\
\hline Education $\geq 16$ years, $\%$ & 45.9 & 40.4 & 45.5 & 41.2 & 50.6 \\
\hline Married/living as married, $\%$ & 41.2 & 43.9 & 37.4 & 40.5 & 40.7 \\
\hline \multicolumn{6}{|l|}{ Dietary pattern, $\%$} \\
\hline $\begin{array}{l}\text { Fifth quintile of vegetable/fruit } \\
\text { consumption (healthiest) }\end{array}$ & 19.6 & 22.8 & 17.7 & 17.2 & 22.7 \\
\hline $\begin{array}{l}\text { Fifth quintile of meat/fried food } \\
\text { consumption (unhealthiest) }\end{array}$ & 20.4 & 19.8 & 20.9 & 20.8 & 19.3 \\
\hline \multicolumn{6}{|l|}{ Neighbourhood SES, \% } \\
\hline First quintile (poorest) & 19.2 & 20.4 & 19.9 & 21.4 & 16.6 \\
\hline Fifth quintile (richest) & 17.4 & 17.0 & 17.5 & 15.2 & 20.1 \\
\hline Family history of diabetes, $\%$ & 37.5 & 35.7 & 38.6 & 36.0 & 40.8 \\
\hline Non-/never smokers, $\%$ & 64.7 & 64.0 & 64.2 & 68.2 & 59.1 \\
\hline Current alcohol drinkers, $\%$ & 27.2 & 26.3 & 28.3 & 26.0 & 29.3 \\
\hline Vigorous exercise $\geq 5 \mathrm{~h} /$ week, $\%$ & 8.5 & 7.8 & 9.0 & 8.0 & 9.9 \\
\hline Walking for exercise $\geq 5 \mathrm{~h} /$ week, $\%$ & 12.9 & 13.0 & 13.9 & 12.0 & 13.9 \\
\hline
\end{tabular}

Table 2 shows association and mediation analysis results. A total of 5344 incident cases of diabetes occurred during 576,577 person-years of follow-up. In the multivariate model, women with the highest exposure (fourth quartile) to everyday racism had a $31 \%$ increased risk of diabetes. For lifetime racism, women with the highest exposure (yes to all) had a $16 \%$ increased risk of diabetes compared with women who answered no to all questions. Adjustment for dietary patterns did not change the estimates in any appreciable way. Adjustment for BMI greatly attenuated racism associations with diabetes. For everyday racism, the HR controlling for BMI was 1.13 (95\% CI 1.04, 1.22). BMI explained $55 \%$ of the association. For lifetime racism, the addition of BMI to the model resulted in HR 1.07 (95\% CI 0.98, 1.18). BMI explained $52 \%$ of the association.

Table 2 Association of perceived racism and incidence of type 2 diabetes in the BWHS, 1997-2013

\begin{tabular}{|c|c|c|c|c|c|c|c|c|}
\hline \multirow[t]{2}{*}{ Analysis } & \multicolumn{4}{|c|}{ Everyday racism quartiles } & \multicolumn{4}{|c|}{ Summary lifetime racism } \\
\hline & Q1 & Q2 & Q3 & Q4 & No to all & Yes to 1 & Yes to 2 & Yes to 3 \\
\hline No. of cases & 964 & 1486 & 1439 & 1455 & 1474 & 1663 & 1284 & 650 \\
\hline Person-years & 102,486 & 162,891 & 168,065 & 143,135 & 166,567 & 185,637 & 137,627 & 61,495 \\
\hline Age-adjusted $^{\mathrm{a}}$ & 1.00 & $1.03(0.95,1.12)$ & $1.03(0.95,1.12)$ & $1.31(1.21,1.42)$ & 1.00 & $1.00(0.94,1.08)$ & $0.97(0.90,1.04)$ & $1.07(0.97,1.17)$ \\
\hline Multivariate $^{\mathrm{b}}$ & 1.00 & $1.05(0.97,1.14)$ & $1.06(0.98,1.15)$ & $1.31(1.20,1.42)$ & 1.00 & $1.05(0.98,1.13)$ & $1.04(0.97,1.13)$ & $1.16(1.05,1.27)$ \\
\hline $\begin{array}{l}\text { Multivariate } \\
\text { +diet }^{\mathrm{c}}\end{array}$ & 1.00 & $1.04(0.96,1.13)$ & $1.05(0.97,1.14)$ & $1.29(1.19,1.41)$ & 1.00 & $1.05(0.98,1.13)$ & $1.05(0.97,1.13)$ & $1.16(1.06,1.28)$ \\
\hline $\begin{array}{l}\text { Multivariate } \\
+ \text { +BMI }\end{array}$ & 1.00 & $1.00(0.92,1.09)$ & $0.98(0.90,1.06)$ & $1.13(1.04,1.22)$ & 1.00 & $1.03(0.96,1.10)$ & $1.00(0.93,1.08)$ & $1.07(0.98,1.18)$ \\
\hline $\begin{array}{l}\text { Proportion } \\
\text { explained } \\
\text { by BMI, \% } \\
(95 \% \mathrm{CI})\end{array}$ & - & - & - & $55(38,73)$ & - & - & - & $52(26,79)$ \\
\hline
\end{tabular}

Data are HRs (95\% CIs) unless stated otherwise. Reference values: Q1 for everyday racism and No to all for lifetime racism

${ }^{a}$ Adjusted for age and questionnaire cycle

${ }^{\mathrm{b}}$ Adjusted for age, questionnaire cycle, marital status, neighbourhood SES, no. of years of education, family history of diabetes, vigorous activity, walking for exercise, alcohol use and smoking status

${ }^{\mathrm{c}}$ Adjusted for vegetable/fruit and meat/fried food dietary pattern scores 


\section{Discussion}

In this large prospective study of African-American women, we found that high scores of perceived racism were associated with higher incidence of type 2 diabetes.

To our knowledge, ours is the first study to prospectively examine self-reported perceptions of racism in relation to incident diabetes. Cross-sectional studies have explored the relationship between perceived racism and diabetes-related outcomes. Internalised racism has been found to be associated with diabetes diagnosis [6] and elevated fasting glucose [7]. Perceived discrimination was associated with increased complications of diabetes [8].

Chronic stress induced by experiences of racism may affect risk of diabetes through several pathways. Animal and human data suggest that stressors can lead to weight gain [14]. In addition, stress tends to alter the pattern of food consumption, promoting cravings for nutrient-dense 'comfort foods' [14]. Our results show that about half of the association between greater experiences of racism and diabetes is mediated by BMI, and previous BWHS studies have also shown that more frequent experiences of racism were associated with higher weight gain and incident obesity. We did not find evidence of mediation by diet, at least as measured by the vegetable/ fruit and meat/fried food dietary patterns. Because we assessed diet at only two points in time (1995 and 2001), in contrast to BMI, which was updated every 2 years, it is possible that we did not capture small changes in dietary behaviour resulting from exposure to racism. Independent of behavioural mechanisms, chronic stress may lead to long-term activation of the hypothalamic-pituitary-adrenal axis, resulting in alterations of innate immune activity, which may lead to insulin resistance and type 2 diabetes [15].

Strengths of the current study include a large, geographically diverse sample, a prospective study design and a long follow-up. We were also able to control for important confounding factors such as age and SES. Successful cohort follow-up lessened the potential for bias from selective losses. The measures of perceived racism are highly reproducible [3] and have been used previously in the BWHS $[4,5]$. Validation studies were used to assess the accuracy of self-reported diabetes and self-reported weight and to estimate prevalence of undiagnosed diabetes in the cohort.

In summary, this large prospective study of African-American women suggests that perceived racism is associated with a higher risk of incident type 2 diabetes. BMI appears to play an important mediating role. Racial discrimination is an important psychosocial stressor for African-American women [16] and may explain in part the higher burden of obesity and type 2 diabetes among these women. As both type 2 diabetes and obesity are important risk factors for cardiovascular disease, these results underscore the public health importance of continuing antidiscrimination efforts globally and domestically.

Acknowledgements The authors thank the BWHS participants for their continuing participation in this research effort.

Some of these results were included in KLB's doctoral dissertation (Boston University School of Public Health, 2016).

Data availability The Boston University Medical Campus IRB has determined that we may not post individual data to a public repository because the IRB judged that the informed consent provided by study participants is incompatible with such posting. However, the IRB has determined that we can share de-identified data with outside investigators under the following conditions: (1) personal identifiers are removed from all data items and (2) a BWHS investigator is involved in review, interpretation and publication of results of the analysed data. See https://www.bu.edu/bwhs/for-researchers/ for information about the procedure for data request.

Funding This work was supported by grants R01 MD007015 from the National Institute on Minority Health and Health Disparities (National Institutes of Health), R01 CA058420 and UM1 CA164974 from the National Cancer Institute and 11SDG7390014 from the American Heart Association. The content is solely the responsibility of the authors and does not necessarily represent the official views of any of the funding agencies.

Duality of interest The authors declare that there is no duality of interest associated with this manuscript.

Contribution statement All authors made substantial contributions to one or more of the following: the study conception and design, acquisition of data and analysis and interpretation of the data. All authors contributed to drafting and/or revising the article critically for important intellectual content and all authors provided their final approval of the version to be published. EARN is the guarantor of this work.

\section{References}

1. Cowie CC, Rust KF, Byrd-Holt DD et al (2006) Prevalence of diabetes and impaired fasting glucose in adults in the U.S. population: National Health And Nutrition Examination Survey 19992002. Diabetes Care 29:1263-1268

2. Signorello LB, Schlundt DG, Cohen SS et al (2007) Comparing diabetes prevalence between African Americans and Whites of similar socioeconomic status. Am J Public Health 97:2260-2267

3. Williams DR, Yu Y, Jackson JS, Anderson NB (1997) Racial differences in physical and mental health: socio-economic status, stress and discrimination. J Health Psychol 2:335-351

4. Cozier YC, Wise LA, Palmer JR, Rosenberg L (2009) Perceived racism in relation to weight change in the Black Women's Health Study. Ann Epidemiol 19:379-387

5. Cozier YC, Yu J, Coogan PF, Bethea TN, Rosenberg L, Palmer JR (2014) Racism, segregation, and risk of obesity in the Black Women s Health Study. Am J Epidemiol 179:875-883

6. Tull ES, Chambers EC (2001) Internalized racism is associated with glucose intolerance among Black Americans in the U.S. Virgin Islands. Diabetes Care 24:1498 
7. Tull ES, Cort MA, Gwebu ET, Gwebu K (2007) Internalized racism is associated with elevated fasting glucose in a sample of adult women but not men in Zimbabwe. Ethn Dis 17:731-735

8. Peek ME, Wagner J, Tang H, Baker DC, Chin MH (2011) Selfreported racial discrimination in health care and diabetes outcomes. Med Care 49:618-625

9. Rosenberg L, Adams-Campbell L, Palmer JR (1995) The Black Women s Health Study: a follow-up study for causes and preventions of illness. J Am Med Wom Assoc 50:56-58

10. Wise LA, Rosenberg L, Radin RG et al (2011) A prospective study of diabetes, lifestyle factors, and glaucoma among AfricanAmerican women. Ann Epidemiol 21:430-439

11. Vimalananda VG, Palmer JR, Gerlovin H et al (2015) Night-shift work and incident diabetes among African-American women. Diabetologia 58:699-706
12. Wise LA, Palmer JR, Spiegelman D et al (2005) Influence of body size and body fat distribution on risk of uterine leiomyomata in U.S. black women. Epidemiology 16:346-354

13. Coogan PF, Cozier YC, Krishnan S et al (2010) Neighborhood socioeconomic status in relation to 10 -year weight gain in the Black Women s Health Study. Obesity (Silver Spring) 18:2064 2065

14. Scott KA, Melhorn SJ, Sakai RR (2012) Effects of chronic social stress on obesity. Curr Obes Rep 1:16-25

15. Fernandez-Real JM, Pickup JC (2012) Innate immunity, insulin resistance and type 2 diabetes. Diabetologia 55:273-278

16. Clark R, Anderson NB, Clark VR, Williams DR (1999) Racism as a stressor for African Americans. A biopsychosocial model. Am Psychol 54:805-816 